\title{
Illustrating war-time: cartoons and the British and Dominion soldier experience during the Great War, 1914-1918
}

\begin{abstract}
This article assesses how time was depicted within illustrated narratives published in trench newspapers and regimental journals by British and Dominion soldiers as a means of adapting to and enduring the experience of the First World War. Through an extensive archival study of these sources, soldiers' 'comic strips' have been used to demonstrate that time is illustrated as a personal and social experience that enables individuals to comprehend their role within the army. Previous assessments of the experience of time on the battlefields have been dominated by the perception that mechanised warfare induced a fractured and disorientating sense of time. This has traditionally been heralded by scholars as indicating the arrival of a new 'modern era'. However, research findings demonstrate the way in which soldiers illustrated time, the passing of time, the use of order, experience and progress are evident. Far from reflecting the alienating effect of modern warfare, soldiers illustrate 'war-time' as a means by which they inculcate themselves into a military culture and continue their role in the war.

\section{Keywords}

Time, illustrative narratives, comics, trench newspapers, war culture 


\section{Illustrating war-time: cartoons and the British and Dominion soldier experience during the Great War, 1914-1918}

This article examines the way in which the experiences of time are represented in the illustrative narratives produced by American, British and Dominion soldiers during the Great War. These multi-panel ‘proto’ comic strips, largely created by amateur artists for public formats in trench newspapers and regimental journals, reveal some of the ways that soldiers perceived and reacted to the war environment. ${ }^{1}$ This response is significant, as scholars have regarded the battlefields of France, Flanders and Gallipoli as a transformative arena where traditional aspects of perspective, identity and place were challenged. Indeed, the war landscape is regarded in some works as the crucible of the modern age. ${ }^{2}$ Traditionally, this assessment has been based on the work of the war artists and poets whose work characterised the waste and futility of the battlefields. ${ }^{3}$ However, this analysis has been criticised for its focus on an officer class without understanding the wider experience of the war. Using soldiers’ illustrative narratives, which represent the responses of a broader social basis within American, British and

\footnotetext{
${ }^{1}$ Nicholas Saunders, ed. Matters of Conflict: Material Culture, Memory and the First World War (London, 2004).

${ }^{2}$ Modris Eksteins, Rites of Spring: The Great War and the Birth of the Modern Age (Boston, 1989); Jonathan Vance, Death so Noble: Memory, Meaning, and the First World War (Vancouver, 1998).

${ }^{3}$ Samuel Hynes, A War Imagined: The First World War and English Culture (London, 1991).
} 
Dominion armies, this article will examine how the impact of the war on the individual can be examined through their depictions of time at the front and behind the lines. ${ }^{4}$

Through this approach, the 'war culture' of servicemen will be defined; the system of habits, values and beliefs that constitute the mentalities and perspectives which were formed in response to the conflict. ${ }^{5}$ This will enhance the understanding of the experience of servicemen during the Great War; not as an engagement with modernity but as a means to adjust, adapt and continue to participate in the conflict. ${ }^{6}$ The representation of time within multi-panel cartoons serves as a means of visualising the scenes of war as familiar, normalised or 'trivialised'. ${ }^{7}$ Cartoons and comic art have been a highly neglected area of study for scholars of the war. However, as Chapman has demonstrated, the value in assessing this material for understanding the soldier experience is particularly significant. ${ }^{8}$ Indeed, it is through this process of making illustrative sequential narrative cartoons that soldiers endured the effects of the war by imagining and illustrating the conflict.

\footnotetext{
${ }^{4}$ Ross Wilson, Landscapes of the Western Front: materiality during the Great War (London, 2012).

${ }^{5}$ Pierre Purseigle, A very French debate: the 1914-1918 'war culture'. Journal of War and Culture Studies 1(1) (2008), pp. 9-14.

6 Jay Winter, Sites of Mourning, Sites of Memory: The Great War in European cultural history (Cambridge, 1992).

${ }^{7}$ George Mosse, Fallen Soldiers: Reshaping the Memory of the World Wars (Oxford, 1991)

8 J. Chapman and D. Ellin, 'Multi -Panel Comic Narratives as Citizen’s Journalism', Australian Journal of Communication 39(3) (2012), pp. 1-22; J. Chapman, 'The Aussie, 1918-1931: cartoons, digger remembrance and First World War identity’, Journalism Studies 17(4) (2016), pp.415-431.
} 


\section{The First World War: experience, modernity and time}

Time as an individual and collective feature of the First World War experience has not featured prominently within the study of the war. Where time has been the subject of concern, it has been represented as an effect imposed upon soldiers, evidencing either the nature of mechanised warfare or the fractured experience of modernity. ${ }^{9}$ Since the 1970s, a number of studies have been conducted on the experience of the battlefield arena of the First World War which have considered aspects of time as part of soldiers' lives. ${ }^{10}$ These works were driven by the development of oral history, where testimonies provided by veterans illustrated the confusing melee of combat and the terrified confinement of artillery bombardment on the front lines. ${ }^{11}$ Time, in this assessment, was used to evidence the fatigue and trauma of soldiers as they adjusted to the experience of the war. ${ }^{12}$ The disjointed nature of this experience of time has become part of the wider examination of the First World War as representing a break in cultural and social continuity and thereby representing the harbinger of the 'modern world'. ${ }^{13}$ Indeed, within Fussell's ${ }^{14}$ seminal analysis, using the letters, diaries and memoirs of

\footnotetext{
${ }^{9}$ Stephen Kern, The Culture of Time and Space, 1880-1918 (Cambridge, MA, 1993).

${ }^{10}$ John Ellis, Eye-Deep in Hell: Trench Warfare in World War I (Baltimore, 1977); Denis Winter, Death's Men: Soldiers of The Great War (London, 1978).

${ }^{11}$ Martin Middlebrook, The First Day on the Somme (London, 1971).

12 Lyn MacDonald, They Called It Passchendaele (London, 1978); Lyn MacDonald, Somme (London, 1983).

${ }^{13}$ Vincent Sherry, The Great War and the Language of Modernism (Oxford, 2003).

${ }^{14}$ Paul Fussell, The Great War and Modern Memory (Oxford, 1975).
} 
officers, this disorientated sense of time for the soldiers of the British Army is regarded as a confrontation with the forces of the modern world. Forced into a troglodyte existence in the trenches, beset by fear, traumatised by industrialised warfare and by their alienation from society, troops developed a 'modern' perception of order to replace Victorian ideals of martial service and national sacrifice. ${ }^{15}$ This confrontation with the modern world was also examined by Leed, who regarded the effects of the conflict as destabilising well-held notions of progress and identity, which served to transform soldiers' ideas of time and place. ${ }^{16}$ Therefore, where time has featured as an object of concern it has frequently been to emphasise the sense of disorder and chaos wreaked by mechanised warfare.

The fractured experience of time on the battlefields has also been used as a wider device to explain wartime cultural changes. For example, the disorientating experience of the conflict, including the loss of comrades and the mental and physical injuries suffered as a result of combat, have been assessed as resulting in changes in political, social and gendered identities of soldiers. ${ }^{17}$ Traumatic conditions such as shell-shock or 'neurasthenia' are seen to reflect the disturbance of the modern age as

\footnotetext{
${ }^{15}$ Robert Wohl, The Generation of 1914 (Harvard, MA, 1979).

${ }^{16}$ Eric J. Leed, No Man's Land: Combat and Identity in World War 1 (Cambridge, 1979).

17 Joanna Bourke, Dismembering the Male: Men's Bodies, Britain, and the Great War (London, 1996); Graham Dawson, Soldier Heroes: British Adventure, Empire and the Imagining of Masculinities (London, 1994); Jessica Meyer, Men of war: Masculinity and the First World War in Britain (Basingstoke, 2009).
} 
individuals seek to cope with the sense of disjuncture caused by the war environment. ${ }^{18}$ This assessment of the battlefields as a place of physical, mental, social and cultural destabilisation has been prominent within cultural history but is contrasted with the work of military and social historians who over the last two decades have stressed development and evolution on the battlefields rather than transformation. ${ }^{19}$ Indeed, a consistent theme within the 'new wave' of First World War studies that has emerged is its focus on adaptation to the war environment. ${ }^{20}$ This reflects the wider concern for the study of 'war cultures', constituting the mentalities, values and perceptions that are formed by governments, organisations, communities and individuals to understand the conflict. ${ }^{21}$ Here the battlefields are not spaces of alteration but places where individuals adjust to and endure the privations and dangers of the war. ${ }^{22}$

The understanding of time as an individual and as a collective experience is central to this process. Whilst the war may be regarded by historians within the chronological parentheses of '1914-1918', the lived experience of the war was structured on a very different comprehension of time. ${ }^{23}$ Soldiers at the front and behind

\footnotetext{
${ }^{18}$ Wyatt Bonikowski, Shell Shock and the Modernist Imagination: The Death Drive in post-World War I British Fiction (Farnham, 2013).

${ }^{19}$ Stephen Badsey, The British Army in Battle and Its Image 1914-1918 (London, 2009).

${ }^{20}$ Pierre Purseigle, 'Introduction: Warfare and Belligerence: Approaches to the First World War', In Pierre Purseigle ed., Warfare and Belligerence: Perspectives in First World War Studies (Leiden and Boston, 2005), 1-37; Pierre Purseigle and Jenny Macleod, eds., Uncovered Fields: Perspectives in First World War Studies (Leiden and Boston, 2004).

${ }^{21}$ Anette Becker and Stephan Audoin-Rouzeau, 14-18: Understanding the Great War (New York, 2002).

${ }^{22}$ Craig Gibson, Behind the Front: British Soldiers and French Civilians, 1914-1918 (Cambridge, 2014).

${ }^{23}$ Ross Wilson, 'Memory and Trauma: narrating the Western Front, 1914-1918', Rethinking History 13(2) (2009), pp.251-268.
} 
the lines were organised upon military timescales, passed the time with comrades and personally reflected upon the time spent in service. As such, time was both a tool of authority and a point of personal observance which gave meaning to each soldier's involvement in the conflict. ${ }^{24}$ Rather than the fractious and shattered notions of time which have been observed by scholars who assert the arrival of the modern age on the battlefields, time for soldiers was a way of placing meaning and understanding upon the war environment. ${ }^{25}$ Therefore, illustrative narratives produced by soldiers provide a key source of data in assessing the process by which depictions of the war employed time as a structuring device. This material enables a broad understanding of the armed service as it is developed from a wide social base with all social classes using images to depict how a sense of order could be found through personal and collective notions of time. In this manner, the illustration of time was used by soldiers to grow accustomed to the hostility, unpredictability and boredom within the war landscape. Crucially, it was also used to educate new arrivals within military units, to engender association with disciplinary codes and to survive periods of separation from home, understanding time is crucial. ${ }^{26}$ Thus, with a focus on enduring and adapting to the war, the study of time

\footnotetext{
${ }^{24}$ Chris Ward, 'Impressions of the Somme: an experiment', Rethinking History 1(3) (1997), 275-310; Chris Ward, Living on the Western Front: Annals and Stories, 1914-1919 (London, 2013).

${ }^{25}$ See Stephan Audoin-Rouzeau, Men at War 1914-1918: National Sentiment and Trench Journalism in France During the First World War (Oxford, 1992).

${ }^{26}$ See Alexander Watson, Enduring the Great War: Combat, Morale and Collapse in the German and British Armies, 1914-1918 (Cambridge, 2008).
} 
through soldier comics can provide a new means of examining the experience of the First World War.

\section{Time and the 'war culture'}

The study of how time is featured within the wartime illustrations of soldiers from Australia, Britain, Canada and New Zealand further defines the 'war culture' that existed amongst soldiers of the First World War. The caricature sequences drawn in published and private documents enable a means of assessing the processes of adaptation to the war environment from an individual and collective standpoint. This particular evidence has been neglected as a source of data and it is only recently that scholars have drawn attention to its potential. This is perhaps due to the perception of these works as purely entertainment. Certainly, comic illustration provided light relief for soldiers. This was the case with the most famous British example of single-panel illustration in the work of the artist Bruce Bairnsfather (1887-1959). His depiction of the laconic, archetypal British soldier, 'Old Bill', was highly popular on the front and at home. ${ }^{27}$ Whilst well-known comic artists were employed by government and by private publications to provide uplifting images of the war, to inspire the populace and to emphasise the righteousness of the cause, individuals who volunteered or were conscripted into the war also illustrated their experiences. Whereas once these works

\footnotetext{
${ }^{27}$ Bruce Bairnsfather, Fragments from France (London, 1917).
} 
were too easily dismissed as the ephemera of wartime popular culture, they can now be understood as an essential means of understanding how perceptions of the wartime world were formed. ${ }^{28}$ Over the course of the war, soldiers responded to their situation by illustrating life at the front and behind the lines for themselves, for comrades and for those at home. They did this through illustrating specific narratives from their own reaction to experiences which were then communicated to comrades. This transmission of ideas is significant as it is through this process that ideals and values were developed and held in common. ${ }^{29}$

These illustrative works reflect a shared perspective on the conflict which reveals aspects of the soldiers' 'war culture'. ${ }^{30}$ This latter is defined by Jones as:

'...a system of cultural supports that allowed populations to adapt to and perpetuate the conflict' ${ }^{31}$

\footnotetext{
${ }^{28}$ Jane Chapman, Anna Hoyles, Andrew Kerr and Adam Sherif, Comics and the World Wars: A Cultural Record (Basingstoke, 2015); J. Chapman and D. Ellin, 'Dominion cartoon satire as trench culture narratives: Complaints, endurance and stoicism.' The Round Table: The Commonwealth Journal of International Affairs, 103(2) (2014), pp. 175-192.

${ }^{29}$ Tony Ashworth, Trench Warfare, 1914-1918: The Live and Let Live System (London, 1980).

${ }^{30}$ J.G. Fuller, Troop Morale and Popular Culture in the British and Dominion Armies 1914-1918 (Oxford, 1990).

${ }^{31}$ Heather Jones, Violence against Prisoners of War in the First World War (Cambridge, 2011), p. 39.
} 
To assess this 'war culture', this study examines the illustrative work of soldiers who fought within the Australian and New Zealand Army Corps (ANZAC), the British Expeditionary Force and the Canadian Expeditionary Force. The source of these illustrations is principally trench newspapers and regimental journals. The study of these publications has recently increased in prominence as the wider cultural lives of soldiers have been studied. ${ }^{32}$ A sample of 40 illustrations has been taken from trench journals and official publications stored at the Australian War Memorial, Cambridge University Library and the National Library of Australia. These illustrations can be classed as multi-panel ‘proto’ comics, which were a well-established form of entertainment and commentary within Edwardian Anglophone society before the war. Within early twentieth century newspapers and periodicals, illustrations enabled artists to convey a worldview that reflected and informed wider society. With the advent of the war in August 1914, this technique was mobilised both by official, and counterintuitively as individual effect. The material is located in archives across former combatant countries and represents a significant and extensive resource for study. To conduct this analysis, multi-panel cartoons have been the focus of assessment because two panels or more can depict a longer narrative for the depiction of time than a single panel cartoon. The sample was selected by searching all surviving records of British and Dominion trench newspapers for multi panel illustrations. Of the $25 \%$ of records that

\footnotetext{
${ }^{32}$ Graham Seal, The Soldiers' Press: Trench Journals in the First World War (Basingstoke, 2013).
} 
feature such evidence, content was analysed according to broad themes, from which the sample on chronology was categorised, reflecting various notions of time through themes such as 'before and since the war', or 'now' and 'then', providing a detailed picture of adjustment and reaction to time.

Whilst these materials are varied in composition and competence in terms of their artistic execution and merit, they can nevertheless be examined on the same basis through a mode of analysis that assesses the narrative and visual structure of the work. ${ }^{33}$ This approach is based on understanding the illustrations as a narrative composed of various parts; essentially the illustration, as a multi-panel cartoon, is a composite which is formed through the structure of the work and its function for the reader. ${ }^{34}$ This approach to the study of selected illustrative material exposes the role of time as a tool for adaptation. As such, examples are taken from across the period of the war using various different national and regional perspectives to demonstrate that despite the fluctuations of the conflict and the experiences of its combatants, it is the representation of chronology that can form a structuring device. Within the soldiers' cartoons, time is represented through the sequences and actions of the subject as an ordered continuum rather than a disjointed experience. Through illustrating time, soldiers are able to emphasise change and adaptation, demonstrating cause and consequence. In effect, they

\footnotetext{
${ }^{33}$ Neil Cohn, The Visual Language of Comics: Introduction to the Structure and Cognition of Sequential Images (London, 2013).

${ }^{34}$ Thierry Groensteen, The System of Comics. Translated by B. Beaty and N. Nguyen, (Jackson, MS, 2007).
} 
evidence a war experience which is clear and understandable, not fractured or disjointed. Time is key to this process as it is subjective and the product of an individual's perception of their environment; the structured nature of its depiction demonstrates the experience of the soldier. ${ }^{35}$ This can be regarded as an experiential understanding of time, rather than time as an objective, universal effect. ${ }^{36}$ Within such a definition of time as dependent on the individual, time only has relevance and significance because people exist within it. Time, rather than being a neutral constant in the lives of individuals is the product of the relations an individual has with others. ${ }^{37}$ Through this understanding of time, the illustrations of soldiers can be examined as evidence of experience where time is used as a explanative device. The battlefields of the First World War can be observed as a site of adaptation rather than detachment. This study also further demonstrates the value of analysing sequential cartoon art for the study of conflict.

\section{Time: structuring the war landscape}

Overwhelmingly, the process of adaptation to the conflict which is illustrated by soldiers is the way in which individuals and groups adjust to the structure of time which

\footnotetext{
${ }^{35}$ Henri Bergson, Matter and Memory. Translated by N.M. Paul and W. S. Palmer (London, 1911); William James, The Principles of Psychology, Volume 1 (New York, 1890).

${ }^{36}$ Maurice Merleau-Ponty, Phenomenology of Perception. Translated by Colin Smith, Forrest Williams, and David Guerriere (New York, 1962), p.422.

${ }^{37}$ Edmund Husserl, The Phenomenology of Internal Time-Consciousness. Translated by J. S. Churchill (The Hague, 1964).
} 
is imposed by the military authorities. Manuals and training literature used by British and Dominion servicemen all stress the necessity of time in tactical deployment, discipline and skill at arms. ${ }^{38}$ In the 'civilian army' which constituted the forces particularly after 1916, volunteers and conscripts were placed within this institution and drilled on a structured routine very different from any pre-war experiences. The majority of soldier visual narratives, even those that do not employ the format's freedom to exaggerate or fantasise, reflect this aspect of military life. Indeed, depictions of time were used to highlight how individuals adapted to their status as soldiers. Time is used to show the processes of training and the taking on of military values. However, time is also presented as a means of maintaining a domestic or non-military identity. As such, from training camps, labouring duties, marches or billets where soldiers were under a strict regulation of time, to periods of leave, leisure or sickness, time is both a means of inculcation within the army, but also a personal commodity. This duality of experiential time can be observed in the soldier illustrations by the constant point of future reference, the end of the war. The belief that the conflict will end and troops could return home enabled individuals to endure the war, but this promise of a future event is framed within the context of the present where the war had to be fought and won. The illustration of war-time demonstrates how the war was not the shocking

\footnotetext{
${ }^{38}$ See War Office, Field Service Manual, 1914: Infantry Battalion (London, 1914).
} 
arrival of modernity for soldiers but an assertion of order upon a disruptive and at times disorientating world.

The experiences of being imbued with the responses and demands that a military time dictated for those men who were not previously professional soldiers is largely presented through an instructional frame within illustrations. Training camp newsletters, which were edited, published and distributed by soldiers, became the ideal vehicle for these observations and acts of communication. Through the cartoon panels of these publications, new soldiers could be informed of the army's timeframe and how they were supposed to respond whilst seasoned troops could find a shared sense of experience in the depiction of the severity, rigour and deprivations endured as part of training regimes. Therefore, camp routines such as route marches provided a popular subject for cartoon reflection. For example, illustrators in the Listening Post, the trench journal of the 7th Canadian Infantry, used comics to inform and reaffirm the army's concept of time during periods of 'rest'. In a typical, five-panel illustration, entitled 'A Few Days Rest', the arduous nature of military time is depicted. Beginning with a 12 mile march, soldiers are then shown washing their soiled gear, followed by being called to attention by a whistle that disturbs men sitting down in the sun, whilst the men are then shown preparing clothes in readiness for the next day. The entire section is centred 
upon a final frame which features the gruelling nature of 'that last half mile' of the march. ${ }^{39}$

These illustrations depict how soldiers become acquainted and inculcated into the military rhythms of time, routine and the control present within the soldiers’ lives. A four-panel piece published in 1917 in the trench journal of the 3rd West Lancashire Brigade, entitled Kamp Knews, demonstrated how military authority could suddenly encroach upon the life of the soldier and reorganise a sense of time. In this illustration of a timeline of 45 minutes, the opportunity for a period of rest is shown to be a fairly fluid concept depending upon wider circumstances in the war. In the first panel, one soldier tells another at 9.00 a.m. that 'rest' will happen in 3 weeks. In the second panel, at 9.15 a.m. the same soldier tells the other that 'we're going out on Sunday into REST' (sic). Then in the third panel, at 9.30 a.m. the soldier informs his now quivering comrade that 'I've heard we're here a month then we go into another part of the line'. However, the final panel at 9.45 a.m. sees a much relieved soldier being informed that, 'We are certain to go to rest tomorrow I'm told' ${ }^{40}$ The humorous nature of the exchange illustrates the means by which time is managed by the army and how the soldiers' lives were organised on this structure.

\footnotetext{
${ }^{39}$ Anon, 'A Few Days Rest', The Listening Post, Vol. 20, 10 December (1916), p. 129.

${ }^{40}$ Kamp-knews. The officious news-ance of the 3rd West Lancs Brigade RFA, No 22, War Reserve Collection, Cambridge University Library (1917).
} 
Chevrons to Stars, the official publication of the Canadian Training School, which was based in the southern English seaside town of Bexhill-on-Sea, featured illustrations which also commented upon this official organisation of time. In one example from October 1917, which is titled, 'Where Life is Not Monotonous', a series of six drawings with commentary are used to explain 'for our friends at home' the life of the soldier at the training school. The full itinerary of training is relayed to the reader in a jocular manner which nevertheless demonstrates the rigid nature of 'military time'. Each one of the six illustrations is given a title according to the activity undertaken: bayonet fighting, ceremonial, squad drill, 'adventure' (a senior officer's story about a trip to London), map-reading and 'voice culture' (shouting at a battalion). ${ }^{41}$ However, in the same edition, another full page cartoon with hand-written captions is more cynical about the way daily routines are apportioned. It opens with a drawing of a man in bed, who is woken by the tones of loudspeaker music: 'The saddest moment of the day - 6 a.m.'. The time sequence ends, after some ten different training sessions with the caption 'Another illusion gone - the Pomp and Circumstance of Glorious War (sic)'. This is juxtaposed next to drawings of a pick and shovel, and a man hopelessly failing at primitive attempts to surface dig. ${ }^{42}$ Despite the sardonic tone of the comic, the

\footnotetext{
${ }^{41}$ Anon, 'Where Life is Not Monotonous', Chevrons to Stars, October (1917), p.52.

${ }^{42}$ Ibid, p.38.
} 
illustrations demonstrate the enculturation of citizen soldiers within the military ordering of time. ${ }^{43}$

\section{Insert pic 2- Caption: New structured time still allows for reflection on 'another illusion gone’. Chevrons to Stars, Oct.1917, p.38. Cambridge University Library.} Indeed, the depiction of chronology within these comics demonstrates a sense of endurance. Despite the exhausting nature of 'military time' its regularity provided order and a collective experience of troops. Whilst soldiers may remark upon the arduous roles they fulfilled, the monotony contributes to a shared sense of culture within the armed services. As such, the 1918 comic illustration, 'When you wish you'd stayed at Home', which appeared in the semi-official Anzac Bulletin, can be read as less a rejection of military structure and more its grim acceptance. ${ }^{44}$ In this depiction, which details an individual's travels across Belgium, the soldier protagonist is rewarded for his endeavours with the news from the regimental cook, 'Sorry, Dinner's (sic) off'. Military time is not valorised or romanticised but it is shown as necessary. The comic sets out the brutal and tiring nature of soldiering, from one panel that depicts the 2 a.m. alarm call, scenes of exhaustion as soldiers move a horse train through torrential rain and extract the animals from mud-filled holes to a final roll call at 2.30 p.m. at which point the soldier is able to fall out. ${ }^{45}$ In these comics, time is a device organised by the army

\footnotetext{
${ }^{43}$ Edward Madigan, 'Sticking to a Hateful Task: Resilience, Humour, and British Understandings of Combatant Courage, 1914-1918', War in History 20(1), pp. 76-98.

${ }^{44}$ Anzac Bulletin 78, WRB 436 (1918).

${ }^{45}$ Ibid.
} 
for the successful prosecution of the war. For the soldiers, military time is arduous but whilst regularly framed with irony it is never considered time ill-spent.

Whilst military time impacted upon the lives of soldiers, time was also the subject of illustrations which demonstrate a personalised, experiential view of the war. This is conducted through the context of army life, for the use of chronology as a structuring device depends upon the individual acquiring a greater degree of understanding of their life as a soldier. Within this study's sample of 40 sequential cartoon narratives, this is reflected in nearly half of this number being two panel snapshots of 'before' and 'after'. This device was famously employed by the Australian cartoonist Cecil Hartt (1884-1930) whilst serving with the Australian Imperial Force. Hartt's work, published in Humorosities in 1917 was used as an introduction to soldier life for readers back in Australia. ${ }^{46}$ In one classic example, Hartt depicts a 'during' and 'after' leave experience in London. The initial frame shows two cigar-smoking soldiers in uniform being chauffeured around the city. However, in the second frame the two pals sit, dejected, heads in hands, on the pavement, obviously having expended all their money and their luck. In effect, this offers a process of learning and of attuning to life as a soldier serving abroad. 'Before and after', 'imagined and real' or 'then and now' sequences demonstrate the change and alteration that has occurred to the lives of these citizen soldiers.

${ }^{46}$ Cecil Hartt, Humorisities (London, 1917). 
This process of change with time of 'before and after' was reflected upon across a range of private and public illustrative comics from soldiers as it offered a straightforward point of comparison. Amateur soldier artists with a penchant for drawing were quick to adopt this accepted format for communication with their peers. Soldier life was understood through this process and this is demonstrated in a two-panel caricature published in the Anzac Book in 1916 where a rich businessman is transformed into a pipe smoking Australian soldier. Time in this depiction is a leveller and a means by which individuals become part of the wider organisation. This is most acutely illustrated in the 1915 edition of the first Australian trench publication The Dinkum Oil (meaning reliable information in Anzac army slang). This journal was hand-written and reproduced by stencil with considerable difficulties on the slopes of Gallipoli. This edition carried a front page two panel comic entitled 'bomb thrower'. Both of the simple drawings showed hand grenades being thrown, the first one by a scruffy anarchist, with the caption 'old style', the second one captioned 'new style', by a smartly dressed soldier. ${ }^{47}$ The passage of time has thereby enabled every element of society to be part of the war effort.

\section{Insert pic 1 Caption Courtesy of the Australian War Memorial}

\section{Personal time: leave, adjustment and adaptation}

\footnotetext{
${ }^{47}$ The Dinkum Oil, Australian War Museum, Folder 73 (1915).
} 
In contrast to military time and the illustrated chronology of adaptation to the war was personal time spent on leave away from the army. In soldier comics, it was this time, imagined and experienced, that is a significant feature of the work as it reflected individual objectives and a source of shared cultural experiences. Time spent on leave was thereby both personal and collective. For example, in the trench journal, Chronicles of the New Zealand Expeditionary Force, a comic from 1917 details a narrative titled 'A 'Digger's Fourteen Day Leave'. From the moment of departure, this is the account of personal time away from the restrictions of military time. Each of the panels accounts for the soldier's experiences. Day One begins with farewells to comrades in France before sailing to England. Day Two has a return to a domestic setting with the soldier attending a barber's shop and enjoying the paid leave from the front. From Day Three through to Day Seven, the soldier is depicted travelling across London in cabs and on the top level of a double-decker bus, as civilian thrills are sought to contrast with the military experience. Days Eight to Eleven are spent enjoying Charlie Chaplin films, as the time the soldier possesses to himself is devoid of military routine. However, there is a sense that the soldier cannot be apart from the time imposed by army life, as by Days Twelve and Thirteen he is shown to be broke and bored, for 'Blighty' has become a 'rotten place'. In the final panel, entitled 'FINIS', the soldier arrives back at the muddy camp on the Western Front, pausing to reflect to this comrade that, 'I had the time of 
my life'. ${ }^{48}$ The sense of personal time and its relationship to military time is laid bare in this respect: whilst the former may allow freedom and a necessary release, it is the latter which provides purpose and structure.

For dominion soldiers especially, periods of leave in England could be particularly disorientating and result in soldiers seeking the reliable routine of military time once more. The Chronicles of the New Zealand Expeditionary Force features a comic from 1917 examining these perspectives through an illustration named 'Those Four Days in London'. Within the panels, two uniformed New Zealand soldiers encounter London life and its excitement. In one panel, they notice in the distance a pair of well-dressed women approaching. Optimistically, one soldier asks the other 'Is my hat straight?' in preparation for conversation with the ladies. However, on their approach, they realise that the two women were mother and daughter. The two soldiers promptly flee the scene causing the ladies to remark on the 'strange antics' of the 'tribe' of ANZACS. In the final panel, the soldiers are running past a ticket collector at Waterloo Station, clearly anxious to return to their camp at the front and the military structure. In their desire to escape the personal time they have been given, one soldier remarks to the other, 'Give me dear old Sling - bull ring and all' ${ }^{49}$ In effect, time spent

\footnotetext{
${ }^{48}$ Chronicles of the NZEF, War Reserve Collection, Cambridge University Library,104.3-5 (1917-18).

${ }^{49}$ Chronicles of the New Zealand Expeditionary Force, War Reserve Collection, Cambridge University Library 104.1-2, (1917).
} 
away from a domestic setting using 'military time' had ensured that an alternative routine appeared confusing and somewhat lacking in purpose.

However, despite the potential trouble caused by a return to civilian time, the periods spent away from the army was not measured in hours and minutes but in the affect it could induce within the individual. This is demonstrated in a two panel cartoon from 1918 in the Aussie. The first panel depicts the happy scenes of 'going on leave' from the line at the Western Front with a soldier raising his slouch hat, whilst a group of others cheerfully play cards. This is contrasted by their return in the second panel where they doze miserably in an overcrowded railway carriage. No matter how fleeting, it is the time spent away which appears to be the most memorable. For example, in his eight panel narrative in the New Zealand trench journal Kia ora Coo Ee, artist Private David Barker (1888-1946) illustrates '24 Hour Leave' in Cairo. Making this time their own is a significant feature of the cartoon, as it reveals how men invented a cover story about visiting a 'sick cobber' in hospital. In reality, the comic describes how 'we sunk a few boozes, only to end up 'behind the bars in Kasr-el-Nil'. They were found out by their commanding officers and punished by 'C.B.' (confinement to barracks) for seven days. The men's time-based obsession with the need to enjoy every minute of leisure time is forcefully articulated as a conclusion in the final panel of ' 24 Hour Leave'. The three 
men walk across the desert in the sunset, and a caption tells us: 'But my oath it was worth it' ${ }^{50}$

As the war progressed, soldier cartoon humour on the topic of survival over time became more prevalent: here lay true victory, one against time and the freedom to still be alive. A four panel sequence in the Listening Post published in 1918 tackles this key issue for troops. Two soldiers are sat on a bench talking, one is experienced, but the other man is referred to as 'a fresh guy'. Time, in this respect, could be used to poke fun at newly arrived individuals who have yet to acquaint themselves with the nature of the warzone. Therefore, perhaps predictably, the experienced soldier begins the conversation with, 'Why, you miserable shrimp, you don't even know enough to come in out of a shower'. The 'fresh guy' responds to this insult with the retort that he had been keeping out of shrapnel for 'three and a half years' causes astonishment in his comrade. Time is used to measure the experience of an individual and their ability survive in the warzone. ${ }^{51}$ In this manner, illustrating chronology for personal time demonstrates the process of adaptation to the war environment. An individual is measured by the time spent in the war. What had once been a mark of an individual, now reflects their place within the wider military time of the conflict.

\footnotetext{
${ }^{50}$ Kia ora Coo Ee, 15 November (1918), National Library of Australia.

51 The Listening Post, Vol. 30, April (1918), p.15. War Reserve Collection, Cambridge University Library 488.
} 


\section{Insert pic 3 .Caption WRA488, Vol. 30, April 1918, p.15. Cambridge University}

\section{Library.}

\section{Waiting for the war to end}

Certain events within the chronological perceptions of soldiers are apparent within the comics sample. Whilst leave and rest periods appear regularly, it is the assumed end of the war that acts as a structuring device within these illustrations. The conclusion to the conflict is not, however, regarded as means of avoiding duty but appears as a point of achievement through victory. This is the logical end to the narrative of the war. In The Indian, a trench journal for the United States Medical Corps, a comic published in a 1918 edition of the publication represents this sentiment. This sequential narrative comic shows a young, innocent soldier who is making conversation at the barrack room table by asking the question, 'Does anybody know when we're going home?' The next panel demonstrates the response to the request which has presumably been a frequent point of concern from sections of the unit. Another individual sat in the next place has brutally pinned the inquiring soldier's head to the table, furiously waving an axe over him. 'Yes, you cheap comedy artist, we're going home when we get orders to, does that penetrate your concrete skull?'52 Whilst the time difference between 'old hand' and

\footnotetext{
${ }^{52}$ The Indian (1918), War Reserve Collection, Cambridge University Library 569.
} 
'young recruit' is used within this sequence, it also represents the way that the war's end sees individual and collective time merging into one.

However, by the end of the war this connection between 'military time' and 'personal time' begins to form different narratives. Whilst the war was ongoing, the structure and rhythm of the army's sense of time was justifiable. With peace, it ceases to have the same level of significance. This is shown with the December 1918 edition of the Listening Post. A cartoon entitled ‘The Burning Question’ highlights this alteration in the use and perception of time. In this four panel narrative, soldiers are talking of current debates after the cessation of hostilities with the latest newspapers surrounding them. In the first three panels, an officer recounts to an orderly the nature of the international war news, with different aspects relating to Turkey, Austria and Germany’s attitudes towards peace terms. After all this diplomatic talk, the orderly interrupts to ask just one simple question in the final panel, 'Where am I on the Battalion Leave List? ${ }^{53}$ This assertion of individual time over military needs with the Armistice is observed in some comics as a very real threat to the continued duty of soldiers at the front. In the March 1919 edition of the Listening Post, a sequential narrative details the attempt of a soldier to impress a local French woman with his war stories whilst leading a donkey who had been at the front 'since Mons'. The animal, a

\footnotetext{
53 Anon, 'The Burning Question', The Listening Post, December (1918). War Reserve Collection, Cambridge University Library 488.
} 
veteran of so much of the conflict, endures the soldier's fabricated account for a while before kicking out against him and reminding him that 'there’s still a war on' ${ }^{54}$

Whilst comics provided a highly suitable means to adjust to the environment of the war, in the post-war world they also became an important form of preserving the memory of the conflict and as a voice for dissent. Time in this sense become a contested object, as whilst the memorials and monuments which were built in the aftermath of the war essentially anchor a sense of time, comics provided a forum to challenge the progress that the war has brought. By 1920 the disappointments of returning veterans were beginning to emerge in their cartoons. This was demonstrated in the last editions of the trench journals, some of which continued until the 1920s as troops were slowly demobilised. In the classic form of a two panel comparison illustration, entitled 'The Profiteer' which appeared in the June 1920 edition of the Aussie, ${ }^{55}$ the first panel is captioned 'France 1918' and shows a war weary soldier walking through mud, burdened with kit, and surrounded by a barren landscape. In the second panel, the landscape is also barren, but it is hot and sunny, and captioned 'Aussie, 1920'. The same man is now a hobo burdened with a backpack of bedding and carrying a billy-can in his hand, this time sweating, but otherwise in exactly the same position on the page as in the first panel, in terms of his physical profile.

\footnotetext{
${ }^{54}$ The Listening Post, March 1919. War Reserve Collection, Cambridge University Library 488.

55 The Aussie, 15 June, (1920).
} 


\section{Conclusions}

Time for soldiers during the First World War was a concept that both saw their integration into the army, becoming part of a wider institution, and marked their own sense of survival as well as adaptation during the conflict. What makes 'military time' and 'personal time' so important for understanding the war experience is how these notions of time are so frequently entwined. The effect of industrialised war was not to signify the arrival of a modern age where traditional ideas were dismissed or made irrelevant. Indeed, what marked the conflict was the way in which soldiers adapted or altered within this new context. The time experienced by soldiers in the war was structured and understandable, placing meaning upon the way in which they became part of the wider war effort. 'Military time' could be brutal, grueling and at times wholly unpredictable but within these illustrated narratives it becomes a point of cultural observance and purposeful. Though soldiers might find themselves placed at the sharp end of military orders it always appears as time 'well-spent'. This can be contrasted with the experience of personal time within these comics which sees soldiers escaping the structures and strictures of army life in wholly unstructured ways. Though useful as a point of escape, frequently within soldier comics, personal time assumes a role that is less purposeful than the role of military time. The former serves the individual whilst the latter, despite its hardships, enables victory. Whilst periods of rest, leave and the end of the war were chronological points that structure soldiers 
perceptions of time, this experience of order and purpose demonstrates how individuals adapted to their role within the army. Soldier comics provide an alternative form of evidence to understand the experience of the war, and by illustrating war-time they highlight the 'war culture' that developed amongst the ranks, enabling survival, endurance and commitment to the cause.

\section{Acknowledgements}

Reproduction of images courtesy of Cambridge University Syndic.

\section{Funding}

This work was supported by the Arts and Humanities Council (AHRC) collaborative research grant: 'Comics and the World Wars, a Cultural Record', 2011-15 [grant number AH/I022120/1]. 